¿Cómo es POSible La Legitimada POR VÍA DE LEGalidad? 


\title{
¿Cómo es POSible la legitimada POR vía de LEGALIDAD? ${ }^{1}$
}

\author{
JÜNGER Habermas ${ }^{2}$ \\ Universidad JohanN WolfGang GoETHE, \\ Fráncfort del Meno, Alemania
}

\section{RESUMEN:}

Voy a sostener la tesis de que la autonomización del sistema jurídico no puede significar una desconexión completa de derecho y moral, por un lado, y de política, por otro. El derecho, al convertirse en positivo, no rompe sus relaciones internas con la moral y la política. En la primera parte voy a bosquejar, a grandes rasgos, cómo el derecho moderno, con ayuda del Derecho Natural Racional, se diferenció del complejo tradicional que formaban moral, derecho y política. En la segunda parte me ocuparé de la cuestión de cómo del hundimiento del Derecho Natural Racional surge una idea de Estado de Derecho que de ninguna manera se limita a flotar impotentemente sobre una sociedad de alta complejidad y acelerado cambio. En Ja tercera parte, finalmente, estudiaré, desde una perspectiva interna, cómo derecho y moral se complementan hoy a la vez que se entrelazan.

1 Artículo publicado en DOXA, Cuadernos de Filosofía del Derecho, N. 5 , 1988, pp. 21-45.

2 Universidad Johann Wolfgang Goethe, Francfurt del Meno, Alemania. Fue profesor de Filosofía en Heidelberg y profesor de Filosofía y Sociología en Francfurt. Entre 1971 y 1980 fue Director del Instituto Max Planck en Stamberg. Desde 1994, es Profesor emérito de la Universidad Goethe de Francfurt. 
Rev. CAP Jurídica Central N. 4 - agosto 2019, ISSN 2550-6595

I.

\section{RAZÓN Y POSITIVIDAD: SOBRE EL ENTRELAZAMIENTO DE DERECHO, POLÍTICA Y MORAL}

I. 1. Si queremos entender por qué la diferenciación del derecho en modo alguno disuelve por completo el interno entrelazamiento de éste con la política y la moral, lo más adecuado es echar una ojeada retrospectiva sobre el nacimiento del derecho positivo. Este proceso se extiende en Europa desde fines de la Edad Media hasta las grandes codificaciones del siglo XVIII. También en los países del common law el derecho consuetudinario queda reorganizado bajo la influencia del derecho romano por el influjo ejercido por juristas de formación académica; en ese proceso el derecho queda sucesivamente adaptado a las condiciones del tráfico de la economía capitalista emergente y al poder burocrático de los Estados territoriales que entonces nacen. De este complicado proceso, rico en variantes y difícil de abarcar, voy a limitarme a un punto de especial importancia en el contexto de nuestras consideraciones relativas a filosofía del derecho. Lo que esa positivación del derecho filosóficamente significa puede entenderse mejor sobre el trasfondo de la estructura trimembre del sistema jurídico medieval, que entonces se derrumba.

Desde una cierta distancia cabe todavía reconocer en nuestras propias tradiciones jurídicas correspondencias con aquellos tres elementos, que de acuerdo con algunos planteamientos de sociología jurídica comparada, habrían conformado la cultura jurídica de las viejas civilizaciones ${ }^{3}$. El sistema jurídico se ve coronado en estas culturas premodernas por un derecho sacro

UnGER, R. M. Law and Society. Nueva York, 1976. 
que se encargan de administrar e interpretar en cada caso especialistas en teología y en derecho. La pieza nuclear de ese sistema jurídico la constituye el derecho burocrático, puesto por el rey o emperador (quien es al mismo tiempo juez supremo) en concordancia con aquellas tradiciones de derecho sacro. Y ambos tipos de derecho se encargan de dar forma a un derecho consuetudinario, por lo general no escrito, que en última instancia proviene de las tradiciones jurídicas de cada etnia. En el Medievo europeo las cosas eran algo distintas, por cuanto que el Derecho Canónico de la Iglesia católica significó el mantenimiento ininterrumpido de la elevada técnica jurídica y conceptual del Derecho Romano clásico, mientras que el derecho burocrático de los edictos y leyes imperiales, incluso antes del redescubrimiento del Corpus Iustinianum, a lo menos conectaban con la idea de Imperium Romanum. Incluso el derecho consuetudinario se debía a la cultura jurídica mixta romano-germánica de las provincias occidentales del imperio y desde el siglo Xll fue objeto de transmisión escrita. Pero en los rasgos esenciales se repite la estructura que nos es conocida por todas las culturas superiores: la ramificación en derecho sacro y derecho profano, quedando el derecho sacro integrado en el horizonte de una de las grandes religiones universales, que se refieren al orden del cosmos o a una historia de la salvación. Este derecho divino o natural no está a disposición del príncipe, sino que representa más bien el marco legitimador dentro del cual el príncipe, a través de sus funciones de administración de justicia y de posición (creación) burocrática del derecho, ejerce su dominio profano. En este contexto habla Max WEBER del doble reino de la dominación tradicional ${ }^{4}$.

4 Cfr. sobre este tema, SCHLUCHTER, W. Die Entwicklung des okzidentalen Rationalismus. Tubinga,1980. 
También en el Medievo se conserva este carácter tradicional del derecho. Todo derecho recibe su modo de validez del origen divino de un derecho natural interpretado en términos cristianos. No puede crearse nuevo derecho si no es en nombre de la reforma o restauración del buen derecho antiguo. Pero esta vinculación a la comprensión tradicional del derecho contiene ya una interesante tensión, que se da entre los dos elementos del derecho del príncipe. Como juez supremo, el príncipe está sometido al derecho sacro. Pues sólo así puede transmitirse la legitimidad de ese derecho al poder profano. De este respeto transido de pietas ante un orden jurídico intangible recibe su legitimación el ejercicio del poder político. Pero al mismo tiempo, el príncipe, que está situado en la cúspide de una administración organizada por cargos, hace también uso del derecho como un medio que otorga a sus mandatos, por ejemplo en forma de edictos, un carácter obligatorio para todos. Por este lado, el derecho como medio del ejercicio del poder burocrático, sólo puede cumplir, empero, funciones de orden, mientras mantenga, por el otro, en forma de tradiciones jurídicas sacras, su carácter no instrumental, ese carácter que lo sitúa por encima del príncipe y que éste ha de respetar en su jurisprudencia. Entre esos dos momentos, el del carácter no instrumental del derecho que se presupone en la regulación judicial de los conflictos, y el carácter instrumental del derecho puesto al servicio de un determinado orden político, se da una indisoluble tensión. Esa tensión permanece oculta mientras no se ataque a los fundamentos sacros del derecho, y el pedestal que representa el derecho consuetudinario consagrado por la tradición se mantenga firmemente anclado en la práctica cotidiana ${ }^{5}$.

5 Cfr. SCHLOSSER. Grundzüge der neueren Privatrechtsgeschichte. Heidelberg. 1982. 
I. 2. Pues bien, si se parte de que en las sociedades modernas cada vez pueden cumplirse menos estas dos condiciones, puede uno explicarse la positivación del derecho como una reacción a tales cambios ${ }^{6}$. A medida que las imágenes religiosas del mundo se disuelven en convicciones últimas de tipo subjetivo y privado y las tradiciones de derecho consuetudinario quedan absorbidas por el derecho de especialistas, que hacen un usus modernus de él, queda rota la estructura trimembre del sistema jurídico. El derecho se reduce a una sola dimensión y sólo ocupa ya el lugar que hasta entonces había ocupado el derecho burocrático. El poder político del príncipe se emancipa de la vinculación al derecho sacro y se torna soberano. A él le compete la tarea de llenar por su propia fuerza, por medio de una legislación política, los huecos que deja tras de sí ese derecho natural administrado por teólogos. En adelante todo derecho tiene su fuente en la voluntad soberana del legislador político. Legislación, ejecución y aplicación de las leyes se convierten en tres momentos dentro de un proceso circular único, gobernado políticamente; y lo siguen siendo, aun después de diferenciarse institucionalmente en poderes del Estado.

Con ello cambia la relación que guardaban entre sí aquellos dos momentos que eran el carácter sacro del derecho, por un lado, y la instrumentalidad del derecho, por otro. Cuando se han diferenciado suficientemente los papeles, y en ello radica el significado de la división de poderes, las leyes anteceden a la jurisprudencia. Pero, ¿puede un derecho político, que es susceptible de cambiarse a voluntad, irradiar todavía ese tipo

6 Este aspecto interno es pasado por alto por la interpretación funcionalista de este proceso de positivación; cfr. LUHMANN, N. Rechtssoziologie. Opladen, 1983. 
de autoridad que irradiaba antaño el derecho sacro?, ¿mantiene el derecho positivo todavía un carácter obligatorio, cuando ya no puede recibir su autoridad de un derecho previo y superior, como sucedía antaño con el derecho burocrático en el sistema jurídico tradicional? A estas preguntas el positivismo jurídico ha dado siempre respuestas afirmativas ${ }^{7}$. En una variante, el derecho queda privado de su carácter normativo en general y queda definido exclusivamente en términos instrumentales: el derecho se considera exclusivamente como mandato de un soberano (AUSTIN). Con ello desaparece aquel primer momento del derecho tradicional como un residuo metafísico. La otra variante del positivismo jurídico se atiene a la premisa de que el derecho sólo puede cumplir su función nuclear de regulación judicial de los conflictos mientras las leyes que se aplican mantengan un momento de aquella incondicionalidad que tenían antaño. Pero este momento sólo puede radicar ya en la forma del derecho positivo, no en contenidos recibidos del derecho natural (KELSEN). Desde este punto de vista, el sistema jurídico, separado de la política y de la moral, con la jurisprudencia o administración de justicia como núcleo institucional, es el único lugar que queda, en que el derecho puede mantener su forma por su propia fuerza y con ello su autonomía. En ambos casos el resultado es que de la garantía metasocial de validez jurídica que antaño había representado el derecho sacro, puede prescindirse sin necesidad de buscarle sustituto.

Pero los orígenes históricos, tanto del derecho tradicional como del derecho moderno, hablan contra esta tesis. Pues el derecho antecede al nacimiento del dominio políticamente organizado, es decir, del dominio estatalmente organizado, mientras que el

7 HÖRSTER, N. Recht und Moral. Gotinga, 1972. 
derecho sancionado estatalmente o el poder estatal organizado jurídicamente, surgen simultáneamente en forma de dominación política $^{8}$. Según todas las apariencias, es la evolución arcaica del derecho la que empieza posibilitando la aparición de un poder político, en la que el poder estatal y el derecho estatal se constituyen recíprocamente. En esta constelación es difícil imaginar que alguna vez el derecho pudiera ser absorbido totalmente por la política o quedar escindido por completo del sistema político. Además, puede mostrarse que determinadas estructuras de la conciencia moral jugaron un papel importante en la aparición de la simbiosis entre derecho y poder estatal. Un papel similar juega la conciencia moral en el tránsito del derecho tradicional al derecho positivo profano, asegurado por el monopolio estatal del poder y puesto a disposición del legislador político. Aquel momento de incondicionalidad que incluso en el derecho moderno constituye un contrapeso a la instrumentalización política del medio que es el derecho, se debe al entrelazamiento de la política y el derecho con la moral.

I. 3. Esta constelación se establece por primera vez con la simbiosis entre derecho y poder estatal. En las sociedades tribales $^{9}$ neolíticas operan típicamente tres mecanismos de regulación de los conflictos internos: las prácticas de auto auxilio (alianzas y venganzas de sangre), la apelación ritual a poderes mágicos (oráculos y duelos rituales) y la mediación arbitral como equivalente pacífico de la violencia y la magia. Pero tales mediadores carecen todavía de la competencia de decidir las disputas de las partes de forma vinculante y dotada de autoridad o

8 Sobre lo que sigue, cfr. WeSEL, U. Frühformen des Rechts. Frankfurt, 1984.

9 Cfr. WesLer, U. loc. cit., p. 329 y ss. 
de imponer sus decisiones incluso contra el juicio de las lealtades dictadas por el sistema de parentesco. Junto con esta característica de urgibilidad, se echan también en falta los tribunales de justicia y los procesos y procedimientos judiciales. Además, el derecho permanece todavía estrechamente hermanado con la costumbre y las representaciones religiosas, de suerte que apenas puede distinguirse entre fenómenos genuinamente jurídicos y otros fenómenos. La concepción de la justicia subyacente a todas las formas de regulación de los conflictos está entretejida con la interpretación mítica del mundo. La venganza, la represalia, la compensación sirven al restablecimiento de un orden perturbado. Este orden, construido de simetrías y reciprocidades, se extiende por igual tanto a las personas particulares y a los grupos de parentesco, como a la naturaleza y a la sociedad en conjunto. La gravedad de un delito se mide por las consecuencias del hecho, no por las intenciones del agente. Una sanción tiene el sentido de una compensación por el perjuicio surgido, no del castigo de un malhechor que se ha hecho culpable de la transgresión de una norma.

Estas ideas concretistas de justicia no permiten todavía una separación entre cuestiones de derecho y cuestiones de hecho. En los procedimientos jurídicos arcaicos confluyen juicios normativos, ponderación inteligente de intereses y afirmaciones relativas a hechos. Faltan conceptos como el de responsabilidad o imputabilidad y culpa. No se distingue entre propósito o intención y comportamiento descuidado. Lo que cuenta es el daño objetivamente causado. No existe separación entre derecho civil y derecho penal. Todas las transgresiones jurídicas son, en cierto modo, delitos que exigen se compensen los daños. Tales distinciones sólo resultan posibles cuando surge un nuevo concepto que revoluciona el mundo de representaciones morales. Me refiero al concepto de norma jurídica independiente de la 
situación, de una norma jurídica que está por encima tanto de las partes litigantes, como del juez imparcial, es decir, de una norma jurídica previa y que se considere vinculante para todos. En torno a este núcleo cristaliza lo que L. KoHLBERG llama conciencia moral convencional. Sin tal concepto de norma el juez sólo puede tratar de convencer a las partes de que lleguen a un compromiso. Para ello puede valerse del influjo que ejerce su prestigio personal, del influjo que ejerce su status, que puede deberse a la riqueza o a la edad. Pero le falta poder político. No puede apelar todavía a la autoridad de una ley que de forma impersonal obligue a todos ni a la conciencia moral de los implicados ${ }^{10}$.

Propongo el siguiente experimento mental: supongamos que antes de que haya surgido algo así como una autoridad estatal se desarrollan ideas jurídicas y morales convencionales (en el sentido de Kohlberg). Entonces un jefe, a la hora (por ejemplo) de resolver un conflicto, puede apoyarse ya en el carácter vinculante de normas jurídicas reconocidas, pero al carácter moralmente vinculante de su juicio no puede añadirle todavía el carácter fácticamente coercitivo de un potencial de sanción estatal. Y, sin embargo, su papel de jefe, que hasta ese momento descansaba sobre su influjo y prestigio fácticos, puede sufrir un cambio importante. Tres secuencias son importantes en este escenario. Tal jefe, en tanto que protector de normas intersubjetivamente reconocidas, participará, en primer lugar, del aura del derecho que él administra. La autoridad normativa del derecho se transmitiría de la competencia de juez al poder de mando del jefe, poder de mando ligado a la competencia de juez por vía de identidad personal. El poder táctico del influyente

10 Posiril, L. "Anthropologie des Rechts. Recht und Gesellschaft", in Archaischen und modernen Kulturen. Munich, 1982. 
se transformaría entonces gradualmente en el poder dotado de autoridad normativa de alguien que puede dar órdenes y tomar decisiones colectivamente vinculantes. Pero para entonces se habría transformado también, en segundo lugar, la cualidad de las decisiones judiciales. Tras las normas jurídicas moralmente obligatorias, no estaría ya sólo la presión que en la vida cotidiana de una tribu se ejerce sobre los individuos para que se conformen a las normas, o el poder fáctico de una persona prominente, sino la sanción con que amenaza un príncipe dotado de poder político legítimo. Habría surgido así el modo de validez ambivalente que caracteriza al Derecho estatal, un modo de validez en que se funden reconocimiento y coerción. Pero con ello, y en tercer lugar, el poder político se habría hecho con un medio con cuya ayuda puede crear una organización de cargos y ejercer burocráticamente ese poder. Como medio de organización, el derecho recibe entonces, junto a su aspecto de incondicionalidad de derecho objetivo, también un aspecto instrumental.

Si bien estas consideraciones tienen también un contenido empírico $^{11}$, lo que ante todo me importa es la aclaración de relaciones conceptuales. Sólo en las imágenes del mundo que se van haciendo cada vez más complejas se forma una conciencia moral de nivel convencional (siempre en el sentido de L. KOHLBERG); sólo una conciencia ligada a normas ancladas en la tradición y moralmente obligatorias hace posible la transformación del poder fáctico en un poder normativo; sólo cuando se dispone de poder legítimo es posible imponer políticamente normas jurídicas; sólo el derecho coercitivo puede utilizarse para la organización del

11 EDER, K. Die Entstehung staatlich organisierter Gesellschaften. Frankfurt, 1976; HABERMAS, J. Zur Rekonstruktion des historischen Materialismus.Frankfurt, 1976. 
poder estatal; si se analiza en detalle este entrelazamiento de moral inserta en una imagen religiosa del mundo, poder jurídicamente legitimado y administración estatal organizada en forma jurídica, resulta clara la insostenibilidad de los dos conceptos positivistas de Derecho, a los que me he referido anteriormente.

I. 4. La reducción de las normas jurídicas a mandatos de un legislador político implica que el derecho se disuelve, por así decirlo, en política. Pero con ello se descompone el concepto mismo de lo político. Pues, bajotal premisa,la dominación política ya no puede entenderse como poder legitimado jurídicamente. Pues un derecho que queda totalmente al servicio del sistema político pierde su fuerza legitimante. En cuanto la legitimación se entiende como operación propia del sistema político, estamos abandonando nuestros conceptos de derecho y política. La misma consecuencia se sigue de la otra idea de que el derecho positivo podría mantener su autonomía por sus propias fuerzas, mediante las operaciones dogmáticas de un sistema judicial fiel a la ley, autonomizado frente a la política y a la moral. En cuanto la validez jurídica pierde toda relación moral ( $\mathrm{y}$, por tanto, toda relación que vaya más allá de la decisión del legislador) con los aspectos de justicia, se torna difusa la identidad del derecho mismo. Pues se pierden entonces los puntos de vista legitimadores bajo los que el sistema jurídico pudiera verse obligado a mantener una determinada estructura.

Si damos por sentado que las sociedades modernas no pueden renunciar al derecho (ni con el pseudónimo de derecho pueden sustituirlo por otro equivalente funcional, es decir, por una práctica de tipo completamente distinta) la positivación del derecho plantea un problema, incluso ya por razones conceptuales. Pues al derecho sacro desencantado -ya un 
derecho consuetudinario vaciado, que ha perdido su sustanciahay que buscarle un equivalente que permita al derecho positivo mantener un momento de incondicionalidad. Se trata del equivalente que en el mundo moderno se desarrolló primero en forma de Derecho Natural Racional, el cual no sólo fue importante para la filosofía del derecho, sino que, en lo que a dogmática jurídica se refiere, tuvo una importancia directa para las grandes codificaciones y para la práctica judicial de desarrollo del derecho ${ }^{12}$.

En este contexto quisiera llamar la atención sobre dos puntos: a) en el Derecho Natural Racional se articula una etapa nueva, postradicional, de la conciencia moral, que liga el derecho moderno a principios y lo asienta sobre el terreno de una racionalidad procedimental; b) Unas veces fue la positivación del derecho como tal y otras la necesidad de fundamentación nacida de esa positivación lo que pasó a primer plano como fenómeno necesitado de explicación; correspondientemente, las teorías del contrato social se desarrollaron en direcciones opuestas. Pero en ninguno de los dos casos lograron establecer una relación plausible entre los momentos de incondicionalidad e instrumentalidad, que caracterizan al derecho.

Ad a) El Derecho Natural Racional reacciona al hundimiento del derecho natural basado en la religión y en la metafísica y a la desmoralización de una política interpretada crecientemente en términos naturalistas y guiada por intereses de autoafirmación. En cuanto el Estado monopolizador de la violencia, logra, en su papel de legislador soberano, convertirse en fuente exclusiva del derecho, este derecho rebajado a medio de organización corre

WIAKER, F. Privatrechsgeschichte der Neuzeil. Gotinga, 1969, p. 249 y ss. 
el riesgo de perder toda relación con la justicia y con ello su genuino carácter de derecho. Con la positividad de un derecho que se vuelve dependiente del soberano estatal, no desaparece la problemática de la fundamentación, sino que no hace más que desplazarse hacia la base ahora mucho más estrecha que representa una ética profana, de tipo postmetafísico y desligada de las imágenes religiosas del mundo.

La figura más básica del derecho privado burgués es el contrato. La autonomía del contrato capacita a las personas jurídicas privadas para generar derechos subjetivos. Pues bien, en la idea del contrato social, esa figura de pensamiento es objeto de una interesante interpretación, para justificar moralmente el poder ejercido en forma de derecho positivo, para justificar moralmente la dominación legal-racional (en el sentido de WeBER). Un contrato que cada individuo autónomo concluye con todos los demás individuos autónomos sólo puede tener por contenido algo que razonablemente redunde en el bien de cada uno. Por esta vía sólo resultan aceptables aquellas regulaciones que puedan contar con el asentimiento no forzado de todos. Esta idea básica delata que la razón del derecho natural moderno es esencialmente razón práctica, la razón de una moral autónoma. Esta exige que distingamos entre normas y principios y procedimientos justificatorios, procedimientos conforme a los cuales podamos examinar si las normas, a la luz de principios válidos, pueden contar con el asentimiento de todos.

Con la idea de contrato social, al ponerse en juego tal procedimiento para la justificación de los órdenes políticos organizados jurídicamente, el derecho positivo queda sometido a principios morales. Desde la perspectiva de una lógica evolutiva (en el sentido de PIAget) resulta obvia la hipótesis de que en el 
tránsito a la modernidad es de nuevo un cambio de la conciencia moral el que marca la pauta a la evolución del derecho.

Ad b) El Derecho Natural Racional aparece en versiones distintas. Autores como HobBes se sienten más bien fascinados por el fenómeno de que el derecho puede cambiarse a voluntad; autores como KANT se sienten fascinados por el déficit de fundamentación de ese nuevo derecho que se ha vuelto positivo. Como es sabido, HobBes desarrolla su teoría bajo premisas que privan tanto al derecho positivo como al poder político de todas sus connotaciones morales; el derecho establecido por el soberano ha de arreglárselas sin un equivalente racional del derecho sacro desencantado. Pero, naturalmente, al desarrollar una teoría que no hace sino ofrecer a sus destinatarios un equivalente racional de aquel derecho sacro, HoBbes se ve envuelto en una contradicción realizativa (en el sentido que da a esta expresión K.O. APEL). El contenido manifiesto de su teoría, que explica cómo el derecho totalmente positivado funciona de forma ajena a toda moral, cae en contradicción con el papel pragmático de la misma teoría, que trata de explicar a sus lectores por qué podrían tener buenas razones como ciudadanos libres e iguales para decidir someterse a un poder estatal absoluto.

KANT hace después explícitos los supuestos normativos que la teoría de HobBes lleva implícitos y desarrolla desde el principio su teoría del derecho en el marco de la teoría moral. El principio general del derecho, que objetivamente subyace a toda legislación, resulta para KANT del imperativo categórico. De este principio supremo de la legislación se sigue a su vez el derecho subjetivo originario de cada uno a exigir de todos los demás miembros del sistema jurídico el respeto a su 
libertad en la medida en que esa libertad se pueda poner en concordancia con la igual libertad de todos conforme a leyes generales.

Mientras que para HobBes el derecho positivo es, en última instancia, un medio de organización del poder político, para KANT cobra un carácter esencialmente moral. Pero tampoco en estas versiones más maduras logra el Derecho Natural Racional resolver la tarea que él mismo se propone de explicar racionalmente las condiciones de legitimidad de la dominación legal. Hoвbes sacrifica la incondicionalidad del derecho a su positividad, en KANT el derecho natural o moral, deducido apriori de la razón práctica, cobra tal predominio, que el derecho amenaza con disolverse en moral: el derecho queda rebajado a un modo deficiente de moral.

KANT inserta de tal suerte el momento de incondicionalidad en los fundamentos morales del derecho, que el derecho positivo queda subsumido bajo el Derecho Natural Racional. En ese derecho, integralmente prejuzgado por el Derecho Natural Racional, no queda espacio alguno para el aspecto instrumental del derecho, del que el legislador político ha de servirse en las tareas de dirección que le competen. Tras hundirse el baldaquino del derecho natural cristiano, no quedan sino las columnas que representan una política interpretada en términos naturalistas, por un lado, y un derecho sustentado por el poder de decisión política, por otro. KANT reconstruye el edificio destruido procediendo a una simple sustitución: el Derecho Natural Racional, fundamentado en términos autónomos, es el encargado de ocupar el puesto vacante que había dejado el derecho natural de tipo religioso y metafísico. Con ello, en comparación con la estructura trimembre del derecho tradicional, cambia ciertamente la función mediadora de la 
jurisprudencia o administración de justicia, que había transmitido la legitimación sacra al príncipe y a su dominación burocrática; ahora la jurisprudencia queda por debajo del legislador político y se limita a administrar los programas de éste. Pero ahora, los poderes del Estado, en sí diferenciados, quedan bajo la sombra de una res publica noumenon deducida a partir de la Razón, que debe encontrar en la res publica phainomenon una reproducción lo más fiel posible. La positivación del derecho, en tanto que realización de principios del Derecho Natural Racional, queda sometida a los imperativos de la razón. Pero si la política y el derecho pasan a desempeñar el papel subordinado de órganos ejecutores de las leyes de la razón práctica, la política pierde su competencia legisladora y el derecho su positividad. De ahí que KANT tenga que recurrir a las premisas metafísicas de su doctrina de los dos reinos para distinguir entre sí, de forma altamente contradictoria, legalidad y moralidad ${ }^{13}$.

13 Kersting, W. Wohlgeordnete Freiheit. Berlín, 1984, p. 16 y ss. 
II.

\section{LA SUSTITUCIÓN DEL DERECHO NATURAL RACIONAL POR LA IDEA DE ESTADO DE DERECHO}

II. 1. El Derecho Natural Racional no sólo se abandonó por razónes filosóficas. La situación que ese derecho trataba de interpretar se hizo tan compleja que le resultó inabarcable. Muy pronto quedó claro que la dinámica de una sociedad integrada a través de mercados ya no podía quedar captada en los conceptos normativos del derecho ni mucho menos podía detenérsela en el marco de un sistema jurídico proyectado a priori. Toda tentativa de deducir de principios supremos, de una vez por todas, los fundamentos del derecho privado y del derecho público, tenía que fracasar ante la complejidad de la sociedad y de la historia. Las teorías del contrato social -y no solamente las idealistas entre ellasestaban planteadas en términos demasiado abstractos. No habían reflexionado sobre los supuestos sociales de su individualismo posesivo. No se habían confesado a símismas que las instituciones básicas del derecho privado, que son la propiedad y el contrato, así como los derechos subjetivo-públicos de protección frente al Estado democrático sólo podían prometer justicia bajo las condiciones de una ficticia economía de pequeños propietarios. Simultáneamente, las teorías del contrato social -y no solamente las que procedían en términos aprióricos- estaban planteadas en términos demasiado concretistas. No se habían percatado de la alta movilidad de la situación social y habían subestimado la presión adaptativa que ejerce el crecimiento capitalista y en general la modernización social. 
En Alemania el contenido moral del derecho natural quedó separado de la teoría del derecho y fue primero proseguido por las vías paralelas que representan la dogmática del derecho privado y la idea de Estado de Derecho, para quedar después vaciado en términos positivistas en el curso del siglo XIX. Desde el punto de vista de la ciencia jurídica el derecho se agotaba en lo esencial en el código civil administrado por juristas. Aquí, en el sistema del derecho privado mismo, no por parte de un legislador democrático, habían de quedar asegurados los contenidos morales del derecho ${ }^{14}$. F. C. von SAVIGNY, que construyó la totalidad del derecho privado como un edificio de derechos subjetivos, opinaba, siguiendo a KANT, que la forma del derecho subjetivo es en sí misma moral. Los derechos subjetivos generales delimitan ámbitos de autonomía privada y garantizan la libertad individual por vía de facultades individuales. La moralidad del derecho consiste en que a la voluntad individual se le señala un ámbito en el que puede dominar con independencia de toda voluntad extraña ${ }^{15}$. Pero con el desarrollo fáctico del derecho quedó claro que los derechos subjetivos son algo secundario frente al derecho objetivo y que ni siquiera son capaces de ofrecer la base conceptual para el sistema del derecho privado. El concepto de derecho subjetivo es objeto entonces de una reinterpretación positivista y queda purificado de todas sus asociaciones normativas. Según la definición de B. WINDSCHEID los derechos subjetivos se limitan a transformar los mandatos del orden jurídico objetivo en facultades de sujetos jurídicos individuales.

14 CoING, H. “Das Verhältnis der positiven Rechtswissenschaft zur Ethik im 19. Jahrhundert", in Blühdorn, J. und Ritter, J. (eds.). Recht und Freiheit. Frankfurt, 1970, p. 11 y ss.

SAVIGNY, F. C. von. System des heutigen Römisches Rechts. T. I, 1940, p. 333. 
Una evolución paralela puede constatarse en la evolución de la idea de Estado de Derecho, que KANT, notémoslo bien, sólo había introducido bajo reservas hipotéticas. Los teóricos alemanes del siglo XIX están interesados ante todo en domesticar en términos constitucionales el poder administrativo de los monarcas. MöHL y WelKer todavía defienden en el Vormärz que las leyes abstractas y generales son el medio apropiado para fomentar por igual en todos los ciudadanos el desarrollo más multilateral posible, y racional, de todas las fuerzas espirituales y corporales $^{16}$. Pero tras la fundación del Reich, GERBER y LABAND desarrollan ya la teoría de la ley, como mandato del soberano, de una instancia legisladora no ligada en lo que a contenidos se refiere. Es este concepto positivista de ley el que, finalmente, los constitucionalistas progresistas de la República de Weimar, tales como HeLLER, suponen al legislador parlamentario: En el Estado de Derecho se llaman leyes, sólo las normas jurídicas dictadas por la asamblea legislativa y todas las normas jurídicas dictadas por la asamblea legislativa ${ }^{17}$.

Me he detenido a recordar este desarrollo, que no es un desarrollo del que pueda decirse que sea típicamente alemán, porque en él la erosión que experimenta ese concepto de ley moralizado en términos de Derecho Natural Racional, puede explicarse desde la doble perspectiva del especialista en dogmática jurídica y del juez, por un lado, y del legislador, poco a poco parlamentarizado, por otro. En los países anglosajones, en que la idea de Estado de Derecho se desarrolló desde el principio como rule of law

16 Cfr. MAuss, I. "Entwicklung und Funktionswandel des bürgerlichen Rechtstaat", en Tohidipur, M. (ed.). Der bürgerliche Rechtstaat. T. I, Frankfurt, 1978, p. 13 y ss.

17 Heller, H. Ges. Schriften. T. II, Leiden, 1971, p. 226. 
en consonancia con los desarrollos democráticos, el proceso judicial equitativo (fair and due process) fue el modelo de interpretación unitaria que se aplicó a la legislación a la vez que a la jurisprudencia o administración de justicia. En Alemania, la destrucción positivista del Derecho Natural Racional se efectuó por dos caminos separados. Ciertamente que tanto en la dogmática del derecho privado como en la teoría del derecho constitucional queda desmentida la construcción de KANT, conforme a la cual política y derecho quedaban sometidos a los imperativos morales del Derecho Natural Racional -pero ello por una doble vía, a saber: desde el punto de vista del sistema judicial, por un lado, y desde el punto de vista del legislador político, por otro. De ahí que a aquellos que, tras el hundimiento de la construcción que representó el Derecho Natural Racional, tampoco quedaron muy convencidos por la alternativa que representaba el positivismo jurídico, el mismo problema se les presentará de forma distinta por ambos lados.

Al problema se le puede dar en términos generales la siguiente versión. Por un lado, los fundamentos morales del derecho positivo no pueden explicarse en forma de un Derecho Natural Racional superior. Por otro lado, tampoco se los puede liquidar sin sustituirlos, so pena de privar al derecho de ese momento de incondicionalidad del que esencialmente necesita. Pero entonces hay que mostrar cómo en el interior del derecho positivo mismo puede estabilizarse el punto de vista moral de una formación imparcial del juicio y de la voluntad. Para satisfacer esta exigencia no basta con que determinados principios morales del Derecho Natural Racional queden positivados como contenidos del derecho constitucional. Pues de lo que se trata es precisamente de la contingencia de los contenidos de un derecho que puede cambiarse a voluntad. La moralidad integrada en el derecho 
positivo ha de tener más bien la fuerza trascendendora de un procedimiento que se regula a sí mismo, que controla su propia racionalidad.

II. 2. Bajo la presión de este problema, aquellos sucesores de SAvignY que no querían darse por contentos con la interpretación positivista de los derechos subjetivos trataron de convertir al derecho científico de los juristas en fuente de legitimación. SAVIGNY, en su teoría de las fuentes del derecho, había asignado aun a la justicia y a la dogmática jurídica, la tarea todavía modesta y derivada de poner en forma científica ante la conciencia, y de exponer, el derecho positivo procedente de la costumbre y la legislación ${ }^{18}$. En cambio, G. F. PUCHTA sostiene a fines de siglo la idea de que la producción del derecho no ha de ser sólo asunto del legislador político, pues de otro modo el Estado no se fundaría en derecho, es decir, no podría ser Estado de Derecho. Antes bien, compete a la justicia, yendo más allá del derecho vigente, la tarea productiva de una prosecución y complementación constructivas del derecho vigente, dirigidas por principios ${ }^{19}$. Este derecho de los jueces habría de obtener del método científico de fundamentación, es decir, de los argumentos de una jurisprudencia que procede científicamente, esa autoridad independiente que PuchTa quiere atribuirle. Ya PUCHTA ofrece un punto de apoyo para una teoría, que, desde la perspectiva de la jurisprudencia, hace derivar de una racionalidad procedimental inserta en el propio discurso jurídico los fundamentos legitimadores de la legalidad.

Desde la perspectiva dellegislador, resulta obvia una interpretación análoga, aun cuando la discusión parlamentaria se enderece

18 Savigny, F. C. von. Allgemeine Natur der Rechtsquellen. 1840, p. 44.

19 Puchta, G. H.Vom Recht. 1841 , p. 52 y ss. 
directamente a la formación de compromisos y no, como el discurso jurídico, a una fundamentación científicamente disciplinada de los juicios. También por este lado se planteó para aquellos que no podían conformarse con el positivismo democrático de la ley la cuestión de sobre la base de qué razones pueden pretender legitimidad las leyes producidas por mayorías parlamentarias. Ya KANT, siguiendo el concepto de autonomía de RousSEAU, había dado un primer paso para destacar en el procedimiento de la legislación democrática misma el punto de vista moral de la imparcialidad. Como es sabido, KANT convierte en piedra de toque de la juridicidad de cada ley pública el criterio de si podría haber surgido de la voluntad unida de un pueblo ${ }^{20}$. Ciertamente que el propio KANT contribuyó a que en seguida se confundieran dos significados diversos de universalidad o generalidad de la ley: la generalidad o universalidad semántica de la ley abstractamente general vino a sustituir a aquella generalidad procedimental que caracteriza a la ley producida democráticamente como expresión de la voluntad unida del pueblo.

En Alemania, en donde la discusión sobre teoría de la democracia sólo revivió en los años veinte de este siglo, esta confusión tuvo dos desafortunadas consecuencias. Por un lado, se pasó por alto el prolijo onus probandi, que asume una teoría de la democracia, planteada en términos procedimentales, onus probandi que aún hoy está por desempeñar. En primer lugar habría que mostrar en términos de teoría de la argumentación cómo en la formación de la voluntad parlamentaria del legislador se compenetran discursos relativos a objetivos políticos y discursos relativos a fundamentaciones morales con el control jurídico de las normas. En segundo lugar, habría que aclarar en qué se distingue un

KANT, I. Grundlegung der Metaphysik der Sitten. 
acuerdo alcanzado argumentativamente de un compromiso negociado y cómo el punto de vista moral se hace valer a su vez en las condiciones que han de cumplir los compromisos para poder ser considerados fair. Y en tercer lugar, y sobre todo, habría que reconstruir cómo habrían de institucionalizarse por vía de procedimientos jurídicos la imparcialidad de las decisiones del legislativo -empezando por la regla de la mayoría, pasando por las reglas que rigen las discusiones parlamentarias, hasta el derecho electoral y, la formación de la opinión pública en el espacio público político. Este análisis habría de dejarse guiar por un modelo que expusiese la conexión que se da entre los presupuestos necesarios de la comunicación, relativos a la formación discursiva de las decisiones colectivas, y una negociación de intereses que pueda considerarse fair. Sólo sobre este trasfondo podría analizarse críticamente el sentido normativo y la práctica efectiva de tales procedimientos ${ }^{21}$.

Pero además esa confusión de generalidad procedimental y generalidad semántica de las leyes dictadas por el parlamento tuvo como consecuencia que se pasara por alto la problemática autónoma de la aplicación del Derecho. Aun cuando la racionalidad procedimental (una racionalidad plena de contenidos morales) del legislativo quedara suficientemente asegurada institucionalmente, las leyes (se trate o no del derecho regulador que caracteriza al Estado Social) no tienen nunca una forma semántica tal que de ella resulte una determinación que sólo deje al juez una aplicación algorítmica. Como demuestra la hermenéutica filosófica ${ }^{22}$, las operaciones interpretativas

21 NeumanN, U. Juristiche Argumentationslehre. Darmstadt, 1986, p. 70 y ss.

22 EsSER, J. Vorverständnis und Methodenwahl in der Rechtsfindung. Frankfurt, 1972. 
en la aplicación de las reglas comportan siempre operaciones constructivas que desarrollan el Derecho. De ahí que el problema de la racionalidad procedimental se plantee de nuevo de forma distinta para la práctica de las decisiones judiciales y para la dogmática jurídica.

En los procedimientos legislativos, esta moralidad emigrada al Derecho positivo puede imponerse por vía de que los discursos sobre objetivos políticos queden sometidos a las restricciones del principio de que sean susceptibles de asentimientogeneral, es decir, a las restricciones del punto de vista moral que hemos de respetar cuando se trata de fundamentar normas. Pero en una aplicación de normas, que resulte sensible al contexto, la imparcialidad del juicio no queda ya asegurada porque nos preguntemos qué es lo que todos podrían querer, sino preguntándonos si se han tenido adecuadamente en cuenta todos los aspectos relevantes de una situación dada. Antes de poder decidir qué normas, que a veces pueden colisionar entre sí y por tanto han de jerarquizarse a la luz de principios, han de aplicarse a un caso, hay que aclarar si la descripción de la situación es adecuada y completa en lo tocante a los intereses afectados. Como ha demostrado Klaus GüNTHER ${ }^{23}$, en los contextos de fundamentación de normas la razón práctica se hace valer examinando si los intereses son susceptibles de universalización, y en los contextos de aplicación de normas, examinando si se han tenido en cuenta de forma adecuada y completa todos los contextos relevantes a la luz de reglas que pueden colisionar entre sí. Y esto es lo que han de materializar los procedimientos jurídicos que hayan de institucionalizar la imparcialidad de la administración de justicia .

23 GÜNTHER, K. Das Prinzip der Unparteilichkeit und die funktionale Bestimmtheit des Rechts. Ms, 1986. 
II. 3. A lo que apunto con estas consideraciones es a la idea de un Estado de Derecho, con división de poderes, que extrae su legitimidad de una racionalidad que garantice la imparcialidad de los procedimientos legislativos y judiciales. Con ello no se habría obtenido otra cosa que un estándar crítico para el análisis de la realidad constitucional. Y sin embargo, esa idea no se limita a oponerse abstractamente (en un impotente deber-ser) a una realidad que tan poco corresponde a ella. Antes bien, la racionalidad procedimental, emigrada ya parcialmente al derecho positivo constituye (tras el hundimiento del Derecho Natural Racional) la única dimensión que queda en que puede asegurarse al derecho positivo un momento de incondicionalidad y una estructura sustraída a ataques contingentes. 


\section{III.}

\section{LA RACIONALIDAD DE LOS PROCEDIMIENTOS INSTITUCIONALIZADOS JURÍDICAMENTE: CUESTIONES PRELIMINARES}

III. 1. Para que en sociedades de nuestro tipo pueda ser posible una legitimidad mediante legalidad, la fe en la legalidad, que ya no puede contar con las certezas colectivas que antaño habían proporcionado la religión y la metafísica, tiene que apoyarse en cierto sentido en la racionalidad del derecho. Pero tampoco se ha confirmado la suposición de Max WeBER de que la base de la fuerza legitimadora de la legalidad es una racionalidad autónoma, exenta de moralidad, inmanente al derecho como tal. Una dominación ejercida en las formas del derecho positivo, obligadas siempre a justificarse, debe su legitimidad al contenido moral implícito de las cualidades formales del derecho. Pero el formalismo del derecho no debe pensarse en términos excesivamente concretistas ligados a determinados rasgos semánticos, sino que la fuerza legitimadora la tiene los procedimientos que institucionalizan exigencias y requisitos de fundamentación y justificación y la vía por la que se procede al desempeño argumentativo de tales exigencias y requisitos. La fuente de legitimación no debe buscarse tampoco en una sola dirección. No ha de buscarse sólo en un lugar, sea el legislador político o la administración de justicia. Pues bajo las condiciones de una política ligada a las obligaciones del Estado Social, ni siquiera el legislador democrático más cuidadoso puede ligar a la justicia y a la administración mediante la forma semántica de la ley; pues no es posible prescindir del derecho regulatorio ligado al Estado Social. Acerca del núcleo racional (en sentido prácticomoral) de los procedimientos jurídicos, sólo cabe decidir cuando 
se analiza cómo a través de la idea de imparcialidad, tanto la fundamentación de las normas como la aplicación de regulaciones vinculantes establecen una conexión constructiva entre el Derecho vigente, los procedimientos legislativos y los procedimientos de aplicación del Derecho. Esta idea de imparcialidad constituye el núcleo de la razón práctica. Si dejarnos por el momento a un lado el problema de la aplicación imparcial de las normas, la idea de imparcialidad nos aparece desplegada, desde el aspecto sobre todo de fundamentación de las normas, en las teorías de la moral y las teorías de la justicia que proponen un procedimiento para poder enjuiciar las cuestiones prácticas desde un punto de vista moral. La racionalidad de tal procedimiento puro, previo a toda institucionalización, se mide viendo si en él el moral point of view, queda articulado de forma adecuada.

En la actualidad veo tres candidatos serios para tal teoría procedimental de la justicia. Los tres vienen de la tradición kantiana, pero se distinguen por los modelos a que recurren para explicar el procedimiento de toma imparcial de decisiones colectivas ${ }^{24}$. John RAWLS sigue partiendo del modelo del contrato social e inserta en la descripción de la posición original las restricciones normativas bajo las que el egoísmo racional de las partes libres e iguales acaba conduciendo a la elección de principios normativamente correctos ${ }^{25}$. La fairness de los resultados viene asegurada por el procedimiento por el que esos resultados se obtienen. L. KohlberG utiliza, en vez de eso, el modelo de G. H. MEAD de la reciprocidad de perspectivas entrelazadas entre sí. En vez de una posición original idealizada, tenemos una asunción

24 Habermas, J. "Gerechtigkeit und Solidarität”, in EdELstein, W. und Nunner, G. (eds.). Bestimmung der Moral. Frankfurt, 1986.

RAWLS, J. A Theory of Justice. Oxford, 1972. 
ideal de rol (ideal role-taking) que exige del sujeto que juzga moralmente ponerse en lugar de todos aquellos que se verían afectados por la entrada en vigor de la norma en cuestión ${ }^{26}$. A mi juicio, ambos modelos tienen la desventaja de que no hacen del todo justicia a la pretensión cognitiva de los juicios morales. En el modelo del contrato nuestras convicciones morales quedan asimiladas a decisiones de elección racional, y en el modelo de la asunción de rol a ejercicios empáticos de comprensión. De ahí que K. O. Apel y yo hayamos propuesto entender la argumentación moral misma como el procedimiento adecuado de formación de una voluntad racional. El examen de pretensiones de validez hipotéticas representa tal procedimiento porque quien quiere argumentar seriamente ha de estribar en las suposiciones idealizantes que comporta una forma de comunicación tan exigente como es el discurso práctico. Todo participante en una práctica argumentativa tiene que suponer pragmáticamente que en principio todos cuantos pudieran verse afectados podrían participar como iguales y libres en una búsqueda cooperativa de la verdad en la que la única coerción que puede hacerse es la coerción sin coerciones que ejercen los buenos argumentos ${ }^{27}$.

No voy a entrar aquí en las discusiones acerca de teoría moral. En nuestro contexto nos basta constatar que existen candidatos serios para una teoría procedimental de la justicia. Pues sin tal constatación quedaría en el aire mi tesis de que el derecho procedimentalizado y la fundamentación moral de principios remiten el uno al otro. La legalidad sólo puede engendrar

26 Kohlberg, L. The Philosophy of Moral Development. San Francisco, 1981.

27 Habermas, J. Moralbewusstsein und kommunikatives Handeln. Frankfurt. 1983. 
legitimidad en la medida en que el orden jurídico reaccione reflexivamente a la necesidad de fundamentación surgida con la positivación del Derecho, y ello de suerte que se institucionalicen procedimientos jurídicos de fundamentación que sean permeables a los discursos morales.

III. 2. Sin embargo, no deben confundirse los límites entre derecho y moral. Los procedimientos que ofrecen las teorías de la justicia para explicar cómo puede entenderse algo desde un punto de vista moral sólo tienen en común con los procedimientos jurídicamente institucionalizados el que la racionalidad del procedimiento ha de garantizar la validez de los resultados obtenidos conforme a tales procedimientos. Pero los procedimientos jurídicos cumplen aproximativamente las exigencias de una racionalidad procedimental perfecta porque quedan ligados a criterios institucionales y a criterios independientes, recurriendo a los cuales puede establecerse desde la perspectiva de un no implicado si una decisión se produjo o no conforme a Derecho. El procedimiento que representan los discursos morales, es decir, los discursos no jurídicamente regulados, no cumplen esta condición. Aquí la racionalidad procedimental es imperfecta o incompleta. La cuestión de si se ha enjuiciado algo desde un punto de vista moral es algo que sólo puede decidirse desde la perspectiva de los participantes, pues aquí no hay criterios externos o previos. Ninguno de estos procedimientos puede prescindir de idealizaciones, si bien éstas -como ocurre en el caso de los presupuestos de la práctica de la argumentación- no tienen alternativa alguna, es decir, resultan inevitables en el sentido de una necesidad trascendental débil.

Por otro lado, son precisamente las debilidades de una racionalidad procedimental imperfecta de este tipo las que desde puntos 
de vista funcionales explican por qué determinadas materias necesitan de una regulación jurídica y no pueden dejarse a reglas morales de corte postradicional. Sea cual fuere el procedimiento conforme al que hemos de juzgar si una norma podría encontrar un asentimiento no coaccionado, es decir, racionalmente motivado, de todos los posibles afectados, tal procedimiento no garantiza ni la infalibilidad, ni la univocidad ni la obtención del resultado en el plazo deseado. Una moral autónoma sólo dispone de procedimientos falibilistas de fundamentación de las normas. Este alto grado de indeterminación cognitiva se ve además reforzado porque una aplicación (que resulte sensible al contexto) de reglas sumamente abstractas a situaciones complejas -que hay que describir de la forma más adecuada posible y de la forma más completa posible en lo que se refiere a sus aspectos relevantesentraña además una incertidumbre estructural adicional ${ }^{28}$. A esta debilidad cognitiva responde una debilidad motivacional. Toda moral postradicional exige un distanciamiento respecto de las evidencias de las formas de vida en las que aproblemáticamente uno ha crecido. Y tales convicciones morales desconectadas de la eticidad concreta de la vida cotidiana no llevan sin más consigo la fuerza motivacional necesaria que haga también efectivos en la práctica los juicios morales. Cuanto más se interioriza la moral y cuanto más autónoma se vuelve, más se retira al ámbito de lo privado.

De ahí que en todos aquellos ámbitos de acción en que los conflictos, los problemas funcionalmente importantes, y las materias de importancia social exigen tanto una regulación univoca como a plazo fijo, y vinculante, sean las normas jurídicas las encargadas de resolver las inseguridades que se presentarían

GÜNTHER, K. loc. cit. 
si todos esos problemas se dejasen a la regulación puramente moral del comportamiento. La complementación de la moral por un derecho coercitivo puede justificarse, pues, moralmente.

K. O. APEL habla en este contexto del problema de qué puede en definitiva exigirse en el contexto de una ética universalista, que como tal ha de ser por fuerza una ética exigente ${ }^{29}$. Pues, incluso las normas moralmente bien fundadas sólo son exigibles en la medida en que aquéllos que ajusten a ellas su comportamiento puedan esperar que también los otros se comporten de conformidad con esas normas. Pues sólo a condición de una observancia de las normas practicada por todos, cuentan las razones que pueden aducirse para la justificación de tales normas. Pues bien, como de las convicciones morales no cabe esperar que cobren para todos los sujetos una obligatoriedad que en todos los casos las haga efectivas en la práctica, la observancia de tales normas sólo es exigible (si nos situamos en la perspectiva de lo que WEBER llamaba una ética de la responsabilidad) si cobran obligatoriedad jurídica.

Rasgos importantes del derecho positivo se tornan comprensibles si entendernos el derecho desde este punto de vista de una compensación de las debilidades de una moral autónoma. Las expectativas de comportamientojurídicamenteinstitucionalizadas cobran fuerza vinculante mediante su acoplamiento con el poder de sanción estatal. Se extienden a aquello que KanT llamaba aspecto externo de la acción; no a los motivos e intenciones, para los que no se puede forzar a nadie. La administración profesional

29 APEL, K. O. "Kann der postkantische Standpunkt der Moralität noch eimal in subtantielle Sittlichkeit aufgehoben werden?", in Kuhlmann, W. (ed.). Moralität und Sittlichkeit. Frankfurt, 1986. 
del derecho fijado por escrito, público y sistemáticamente configurado, exonera a las personas jurídicas privadas de los costes que se exigen del individuo cuando se trata de la solución moral de los conflictos de acción. Finalmente, el Derecho positivo debe sus rasgos convencionales a la circunstancia de que es puesto en vigor por las decisiones de un legislador político y de que, en principio es cambiable a voluntad.

Esta dependencia del derecho respecto de la política explica también el carácter instrumental del derecho. Mientras que las normas morales son fines en si, las normas jurídicas son también medios para objetivos políticos. Pues no sólo sirven, como ocurre en el caso de la moral, para la solución imparcial de los conflictos de acción, sino también para la puesta en práctica de programas políticos. Los objetivos colectivos y las medidas políticas que los traducen a la práctica deben su fuerza vinculante a su forma jurídica. En este aspecto, el derecho se sitúa entre la política y la moral; y correspondientemente, como ha mostrado DwORKIN, en el discurso jurídico los argumentos relativos a interpretación de las leyes, en el caso de aplicación de éstas, se unen tanto con argumentos relativos a objetivos políticos, como con argumentos relativos a justificaciones morales.

III. 3. La cuestión de la legitimidad de la legalidad ha hecho que en nuestras consideraciones quedara hasta ahora en primer plano el terna derecho y moral. Hemos aclarado cómo se complementan mutuamente un derecho exteriorizado en términos convencionales (siempre en el sentido que a esta expresión da L. Kohlberg) y una moral interiorizada. Pero más que esta relación de complementariedad nos interesa el simultáneo entrelazamiento de derecho y moral. Este se produce porque en el Estado de Derecho se hace uso del derecho positivo como 
medio para distribuir cargas de argumentación e institucionalizar vías de fundamentación y justificación, que se hallan abiertas en dirección a argumentaciones morales. La moral ya no flota sobre el derecho (como todavía sugiere la construcción del Derecho Natural Racional) como un conjunto suprapositivo de normas. Emigra al interior del derecho positivo, pero sin agotarse en derecho positivo. Mas esta moralidad que no solamente se enfrenta al derecho, sino que también queda atada al derecho mismo es de naturaleza puramente procedimental. Se ha desembarazado de todo contenido normativo determinado y ha quedado sublimada en un procedimiento de fundamentación de contenidos normativos posibles. Así, un derecho procedimental y una moral procedimentalizada pueden controlarse mutuamente. En los discursos jurídicos el tratamiento comunicativo de cuestiones práctico-morales queda, por así decirlo, domesticado por vía de institucionalización jurídica; ese tratamiento viene limitado, en lo que a método se refiere, por la vinculación al derecho vigente; en la dimensión objetiva viene limitado en lo tocante a temas y cargas de la prueba; en la dimensión social viene limitado en lo tocante a presupuestos de participación y a inmunidades y distribución de papeles; y en la dimensión del tiempo, en lo tocante a plazos de decisión. Pero, a la inversa, también la argumentación moral queda institucionalizada como un procedimiento abierto, que obedece a su propia lógica y controla así su propia racionalidad. La estructuración jurídica no penetra en el interior de la argumentación de modo que ésta quede atascada en los límites del derecho positivo. El derecho mismo deja en franquía y estimula una dinámica de fundamentación y justificación, que también puede llegar a trascender la letra del derecho vigente, de forma no previsible por éste. 
Naturalmente, que a esta concepción habría que diferenciarla atendiendo a los diversos contextos que representan los discursos que se producen en las ciencias jurídicas, en los tribunales de justicia por parte de los jueces y por parte de los abogados, o también atendiendo a los diversos ámbitos de temas, desde las cuestiones próximas a la moral hasta cuestiones puramente técnicas. Entonces, la correspondiente práctica de toma de decisiones podría reconstruirse también desde el punto de vista de hasta qué punto los procedimientos jurídicos dejan espacio para la lógica de la argumentación o distorsionan sistemáticamente el juego argumentativo mediante restricciones en que implícitamente se hacen valer coacciones externas. Naturalmente, que tales efectos no solamente se reflejan en las regulaciones relativas a procedimientos jurídicos, sino también en el modo como tales regulaciones se llevan a la práctica. A veces se da una clase especial de argumentos que se presta muy bien a tal reconstrucción; en la práctica de decisiones judiciales es fácil, por ejemplo, someter a ese tipo de reconstrucción las fundamentaciones de las sentencias que ponen entre paréntesis puntos de vista normativos para sustituirlos por argumentos relativos a imperativos funcionales que se dan por supuestos. Precisamente en tales ejemplos queda claro que la justicia y el sistema jurídico reaccionan ciertamente a la sociedad, pero que no son autónomos frente a ella. La cuestión de si hay que someterse a imperativos sistémicos, bien sea de la economía o del aparato estatal mismo, incluso cuando tales imperativos quebrantan o merman principios bien fundados, no es algo que en última instancia se decida en los tribunales de justicia, tampoco en el espacio público jurídico, sino en las luchas políticas acerca del trazado de límites entre sistema y mundo de la vida. 
Ahora bien, hemos visto que la fuerza legitimadora, que tiene su asiento en la racionalidad de los procedimientos jurídicos, no sólo se comunica a la dominación legal a través de las normas procedimentales de la jurisprudencia o administración de justicia, sino en mayor grado aún a través de los procedimientos del poder legislativo democrático: Que los procedimientos parlamentarios puedan tener un núcleo racional en sentido práctico moral, no es algo que a primera vista resulte tan plausible. Pues todo parece reducirse a la adquisición de poder político y a una competición (regida por ese poder) de intereses en pugna, de suerte que las discusiones parlamentarias serían accesibles a lo sumo a un análisis empírico, pero no a una reconstrucción crítica conforme al modelo de una negociación fair de compromisos, ni mucho menos de una formación discursiva de la voluntad colectiva. En este lugar no puedo ofrecer ningún modelo satisfactorio. Pero sí quiero subrayar la existencia de toda una serie de teorías de la constitución, centradas en tomo a la idea del proceso que la constitución regula, las cuales se atienen a un planteamiento crítico-reconstructivo $^{30}$. La regla de la mayoría, las normas de procedimiento parlamentario, las leyes electorales, etc., se analizan desde el punto de vista de cómo pueden asegurar en los procesos de decisión parlamentaria que se tengan presentes por igual todos los intereses afectados y todos los aspectos relevantes de la cuestión de que se trate. Una debilidad de estas teorías la veo, no precisamente en este planteamiento como tal, sino en que no desarrollan sus puntos de vista normativos a partir de una lógica de la argumentación moral ni tampoco los aplican a las

30 Choper, J. Judicial Review and National Political Process, 1980; Ely, J. H. Democracy and Distrust. 1980; para una critica de la obra de Ely, cfr. "The Past of Constitutional Theory -and Its Future", in Ohio State Law Journal. 1981, p. 223 y ss. 
condiciones comunicativas que una dinámica de fundamentación ha de cumplir para no resultar distorsionada.

Por lo demás, el proceso intraparlamentario de decisiones sólo constituye un pequeño segmento de la vida pública. La calidad racional de la legislación política no sólo depende de cómo trabajan en el Parlamento las mayorías elegidas y las minorías protegidas. Depende también del nivel de participación y del nivel de formación de los participantes, del grado de información y de la claridad con que en el seno de la opinión pública quedan articuladas las cuestiones de que se trate. La calidad de la vida pública viene en general determinada por las oportunidades efectivas que abra el espacio público político con sus medios de comunicación y sus instituciones. 


\section{CONCLUSIÓN}

La idea de Estado de Derecho, que he tratado de reformular, aunque apunte un poco alto, no por ello resulta delirante, sino que brota del suelo mismo de la realidad jurídica, para convencerse de ello basta tener presente que esa idea es el único criterio que tenemos para medir la autonomía del sistema jurídico. $\mathrm{Si}$ se cerrara esa dimensión en la que las vías de fundamentación jurídica se abren a la argumentación moral, ni siquiera podríamos saber ya qué podría significar eso de autonomía del derecho si no es autonomía sistémica. La autonomía no es algo que un sistema jurídico sobre por sí para sí sólo. Autónomo es un sistema jurídico sólo en la medida en que los procedimientos institucionalizados para la legislación y la administración de justicia garantizan una formación imparcial de la voluntad y del juicio y por esta vía permiten que penetre, tanto en el derecho como en la política, una racionalidad procedimental de tipo ético. No puede haber derecho autónomo sin democracia realizada.

Manuel Jiménez Redondo (Trad.) 